(SHORT COMMUNICATION)

\title{
Why is it difficult to enrol patients in clinical cancer research?
}

\author{
Pereira Ramos Alex 1, ${ }^{*}$, Liberata Barbosa Bandeira Lívia 2, Pereira Ramos Alice Maria ${ }^{3}$, Magro Ferreira \\ Ramon 2, Luíza Meireles Pinheiro Bárbara 2, Pereira Ramos Anita Maria ${ }^{4}$, Barreto da Silva Raphael 5 and \\ Henrique Rala de Paula Bruno 6
}

${ }^{1}$ D'Or Institute for Research and Education (IDOR), Rio de Janeiro, Brazil.

${ }^{2}$ Department of Medicine, University of Vassouras, Vassouras, Brazil.

${ }^{3}$ Department of Medicine, União Metropolitana de Educação e Cultura (UNIME), Lauro de Freitas, Brazil.

${ }^{4}$ Department of Medicine, Faculdade de Tecnologia e Ciências (UNIFTC), Salvador, Brazil.

${ }^{5}$ Department of Medicine, Estácio de Sá University, Rio de Janeiro, Brazil

${ }^{6}$ Cambridge University Hospitals, Cambridge, United Kingdom.

Publication history: Received on 01 May 2020; revised on 20 May 2020; accepted on 21 May 2020

Article DOI: https://doi.org/10.30574/wjarr.2020.6.2.0136

\begin{abstract}
Patient recruitments are a crucial part of clinical research, especially in the medical oncology field. Despite its significance, $2-3 \%$ of patients with cancer participate in clinical trials. Beyond the bureaucratic and financial barriers in most trials, the recruitment can be directly impacted by the study design, referrals and patient beliefs. Therefore, this study points out the difficulties related to the process of patient recruitments in oncology, followed by options that contribute to their improvement.
\end{abstract}

Keywords: Medical oncology; Clinical trials; Patient recruitments; Referrals; Research; Cancer patients.

\section{Introduction}

Advances in oncology directly depend on clinical research. In the past decade, the focus has been on the drug efficacy along with a better toxicity profile. [1] At present, clinical trial designs have become considerably more complex, allowing more personalized treatment. This could potentially avoid unnecessary exposure to patients who are less likely to respond to a specific therapy. [2]

Despite its significance, less than $3 \%$ of patients with cancer participate in clinical trials. [3] Beyond the bureaucratic and financial barriers in most trials, the recruitment can be directly impacted by some factors as the study design, referrals and patients' beliefs. $[4,5,6]$ The relevant factors that make it difficult for patient enrolment and some options to improve them are summarized in Table 1.

In order to avoid bias, study designs focus on diminishing the interference of confounder factors by methodically considering inclusion and exclusion criteria. On the one hand, this method often allows a clear interpretation of the study results without considering bias, which is virtually not possible. On the other hand, the real-world scenario is not a controlled environment. This impairs the generalization of clinical trials and the outcomes are frequently worse when compared with those of clinical practice. Additionally, a considerable number of trials do not reach the recruitment target and they are finalized prematurely. On occasion, this happens without the capability to test the objectives proposed previously in the study.

Strategically, clinical research should be seen as a complementary activity to clinical practice. This could diminish the workload of the teams in clinics as the research team is taking over patient care. As a result of this, it is possible to offer

\footnotetext{
* Corresponding author: Pereira Ramos Alex Tel: +5573991616171 E-mail: alexramosmed@gmail.com
} 
patients other treatment options. The technology of pre-clinical models and contemporaneous study designs allows for a more reliable drug benefit and toxicity prediction, which is the actual aim of what researchers do and patients seek.

Table 1 Factors related to poor recruitment in cancer clinical trials.

\begin{tabular}{|c|c|}
\hline Related Factor & How to improve \\
\hline \multicolumn{2}{|l|}{ Study-related } \\
\hline \multirow{2}{*}{$\begin{array}{l}\text { Restricted inclusion (lines of treatment) and exclusion } \\
\text { criteria (adverse events) }\end{array}$} & Consider broader inclusion criteria \\
\hline & More comprehensive exclusion criteria \\
\hline Some comorbidities are excluded & Control comorbidities on study arms \\
\hline \multicolumn{2}{|l|}{ Referrals-related } \\
\hline \multirow{5}{*}{$\begin{array}{l}\text { High workload impair discussion about research } \\
\text { Major focus on standard therapy } \\
\text { Increased work to refer patients } \\
\text { Studies are scarce in most cancer populations } \\
\text { Fewer research units depending on the geographic area }\end{array}$} & Schedule time to discuss research \\
\hline & Protocol presentation to referral teams \\
\hline & Easier referral procedure (e-mail) \\
\hline & Improve discussion during scientific events \\
\hline & $\begin{array}{l}\text { Less bureaucracy, allowing the creation of new research } \\
\text { units in less central geographic regions. }\end{array}$ \\
\hline \multicolumn{2}{|l|}{ Patient-related } \\
\hline \multirow{6}{*}{$\begin{array}{l}\text { Lack of trust and fear about what is done in clinical } \\
\text { research } \\
\text { Hesitation when using experimental drugs } \\
\text { Wasting time by receiving a placebo } \\
\text { High financial costs due to frequent visits to the study } \\
\text { centre }\end{array}$} & $\begin{array}{l}\text { Improve patient knowledge about the clinical trial through } \\
\text { education according to their level of understanding }\end{array}$ \\
\hline & Offer more information about the study drug; provide an \\
\hline & evaluation by monitoring possible toxicity effects \\
\hline & Avoid placebo whenever possible and explain about the \\
\hline & placebo effect \\
\hline & $\begin{array}{l}\text { Limit to necessary visits and procedures; offer financial } \\
\text { support }\end{array}$ \\
\hline
\end{tabular}

\section{Conclusion}

Therefore, knowing these barriers is the first step to overcome them. Those recommendations should be performed by individualizing the needs of every institution with a focus on patient preferences.

\section{Compliance with ethical standards}

\section{Acknowledgments}

We gratefully acknowledge the support of the collaborative institutions involved in encouraging the elaboration of this article.

\section{Disclosure of conflict of interest}

All of the authors declare they have no conflict of interest, financial or otherwise.

\section{References}

[1] Bhatt A. (2010). Evolution of Clinical Research: A History Before and Beyond James Lind. Perspective In Clinical Research, 1(1), 6-10.

[2] Goldberg RM, Wei L and Fernandez S. (2017). The Evolution of Clinical Trials in Oncology: Defining Who Benefits from New Drugs Using Innovative Study Designs. Oncologist, 22(9), 1015-1019. 
[3] Unger JM, Vaidya R, Hershman DL, Minasian LM and Fleury ME. (2019). Systematic Review And Meta-Analysis Of The Magnitude of Structural, Clinical, And Physician And Patient Barriers To Cancer Clinical Trial Participation. JNCI Journal of the National Cancer Institute, 111(3), 245-255.

[4] Unger JM, Cook E, Tai E and Bleyer A. (2016). The Role of Clinical Trial Participation In Cancer Research: Barriers, Evidence, And Strategies. American Society of Clinical Oncology Educational Book, 35,185-198.

[5] Spencer KR and Mehnert JM. (2016). Importance of including patients with comorbidities in clinical trials. The Lancet Oncology, 17(1), 17-18.

[6] Mills EJ, Seely D, Rachlis B, Griffith L, Wu Ping, Wilson K et al. (2006). Barriers to Participation In Clinical Trials Of Cancer: A Meta-Analysis And Systematic Review Of Patient-Reported Factors. The Lancet Oncology, 7(2), 141148.

\section{How to cite this article}

Ramos AP, Bandeira LLB, Ramos AMP, Ferreira RM, Pinheiro BLM, Ramos AMP, da Silva RBS, and de Paula BHR. (2020). Why is it difficult to enrol patients in clinical cancer research? World Journal of Advanced Research and Reviews, 6(2), 163-165. 